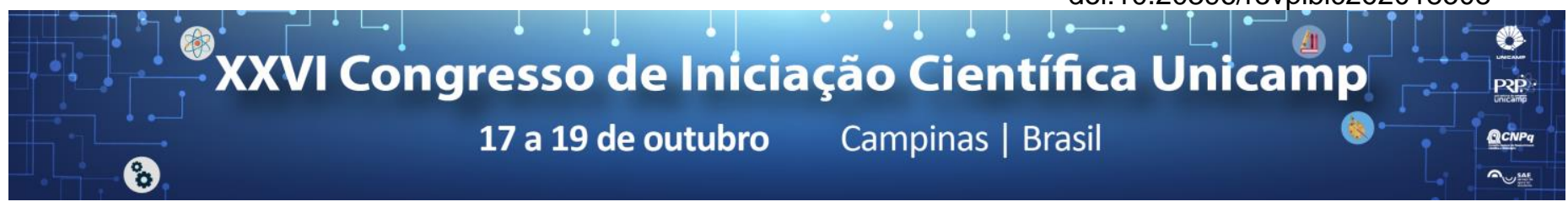

\title{
A iniciação científica e a relação com a formação profissional
}

\section{Cinthia Carla de Oliveria Simião*, Janaina Silva Teixeira de Lima, Sabrina Pindziura Bitencout, Ivo Both, Desiré Luciane Dominschek.}

\section{Resumo}

Esta pesquisa trata, em linhas gerais, da formação de professores compreendendo as dimensões: (i) da iniciação da formação do professor pesquisador; (ii) da aproximação com a prática profissional do docente em instituições educativas, escolas e outras; (iii) da relação entre pesquisa e profissionalização do professor; (iv) das práticas de pesquisa realizadas pelos professores em seu trabalho. A investigação a ser realizada focaliza as séries finais de formação (graduação) e anos iniciais de trabalho procurando estabelecer relações entre formação em pesquisa e suas implicações com a profissionalização do professor. As principais referências internacionais desta pesquisa são: NÓVOA, A. (1992); CARR, W. (2004) e as principais referências nacionais desta pesquisa são; GATTI, B. A. (2006, 2009). Considerando o alcance e significado dos programas de incentivo de fomento à formação do professor, urge indagar a respeito dos impactos desses programas na profissionalização docente. Nesse sentido, a questão básica desta investigação é: "quais são os impactos dos projetos de incentivo à pesquisa no desenvolvimento profissional?" O objetivo desta pesquisa é compreender o impacto dos projetos de iniciação à pesquisa ofertados nos cursos de formação docente aos professores ao longo de sua experiência profissional. Optamos, metodologicamente, por uma abordagem qualitativa, que tenha como escopo as perspectivas fenomenológica e histórico-crítica.

\section{Palavras-chave:}

Formação docente, iniciação científica,pesquisa.

\section{Introdução}

A dimensão da Pesquisa e da Prática Profissional na formação de professores compreende as dimensões: (i) da iniciação da formação do professor pesquisador, (ii) a aproximação com a prática profissional do docente em instituições educativas, escolas e outras, (iii) a relação entre pesquisa e profissionalização do professor; (iv) as práticas de pesquisa realizadas pelos professores em seu trabalho. A investigação a ser realizada focaliza a iniciação da formação em pesquisa e suas implicações com a profissionalização do professor. Situa-se na formação inicial do professor e na formação do professor principiante. Na formação de professor, a pesquisa assume papel didático principalmente nos cursos de formação inicial, as licenciaturas, pois ao mesmo tempo em que o futuro professor compreende a abrangência da docência desenvolve habilidades e capacidades para a realização de investigação em educação. Argumenta André (2001) que a pesquisa possibilita entender a prática, constituir indicativos teóricos sobre o saber docente e contribui com o processo de profissionalização e autonomia do professor.

\section{Resultados e Discussão}

Vale lembrar que na formação de pesquisadores a crítica é contundente na produção da pesquisa realizada em educação, realizada na universidade, em grupos de pesquisa, em teses e dissertações (GATTI, 2006, CHARLOT, 2006, CAMPOS, ) apontando fragilidades na posição e problematização, nos aportes teóricos metodológicos, na realização da análise o que implica em pouca articulação com a prática. No entanto, a integração entre a pesquisa e a prática profissional do docente indicada como necessária Gatti e Barreto (2009), manifesta-se restrita, a interação entre as instituições de formação e de pesquisa com as escolas é limitada, isto é, as escolas e as faculdades e universidades realizam poucos projetos em conjunto.

\section{Conclusões}

Os estudos realizados sobre a formação de professores, apesar de significativos avanços em muitas áreas, ainda carece de uma análise mais aprofundada quanto aos impactos efetivos dos programas de iniciação científica nas práticas docentes. Analisar estes impactos significa pontuar os aspectos positivos e negativos dos programas existentes, apontando para eventuais correções e melhorias nas propostas em andamento.

Pontuar que a pesquisa docente não tem por finalidade somente 0 desenvolvimento de professores pesquisadores, como pode direcionar-se para a realização de trabalhos com a participação conjunta de alunos dos cursos de graduação com professores em exercício de sua função para a construção de referenciais, refinamento de metodologias de pesquisa e de ensino, compartilhamento de problemas e possibilidades de superação

AMARAL, A C P. Soltando-me das pedras. In BUENO, O B; CATANI, D B; SOUSA, C P. (orgs) A Vida e o Ofício dos Professores. Editora Escrituras: São Paulo, 1998. P. 151-157.

ANDRÉ, M. (Org.). O papel da pesquisa na formação e na prática dos professores. 2. ed. Campinas, 2001.

BUEno, O B; CATANi, D B; SOUSA, C P. (orgs.) A Vida e o Ofício dos Professores. Editora Escrituras: São Paulo, 1998.

CARR, W. e KEMMIS, S. Teoria crítica de la enseñanza, Ed. Martinez Roca Barcelona, 1988.

CHARLOT, B. A Pesquisa educacional entre conhecimentos, políticas e práticas: especificidades e desafios de uma área de saber. Revista Brasileira de Educação, v.11, n.31, p.7-18, jan./abr. 2006.

GATTI, B. A. A Pesquisa na pós-graduação e seus impactos na educação. Educação \& Linguagem, v.9, n.14, p.16-33, jul./dez. 2006. 